\title{
EASY GLIDE IN SHEAR BANDS FROM A CALVING ICE WALL DUPLICATED IN LABORATORY CREEP EXPERIMENTS \\ (Abstract)
}

by

Terence Hughes

(Institute for Quaternary Studies and Department of Geological Sciences, University of Maine, Orono, Maine 04469 , U.S.A.)

and

Masayuki Nakagawa

(Department of Physics, Toyama University, Gofuku 3190, Toyama, Japan)

Slab calving from an ice wall on Deception Island $\left(63.0^{\circ} \mathrm{S}, 60.6^{\circ} \mathrm{W}\right)$ has been related to a bending moment at the top of the ice wall that produced nearly vertical shear bands across which shear offset decreases to zero at the bed and in which strain-rates up to $600 / a$ were measured. These shear bands and strain-rates were duplicated in laboratory creep experiments at shear stresses of $100 \mathrm{kPa}$ or more, after a shear strain of about 0.4 at the end of recrystallization. Recrystallization began at a shear strain of about 0.1 when the strain-rate was about $1.9 / \mathrm{a}$, which increases to $24.0 / \mathrm{a}$ after recrystallization. Halving the shear stress suppressed recrystallization. Prior to recrystallization, $n=2.17$ in the flow law, $\dot{\varepsilon}_{z x}=\left(\tau_{z x} / A\right)^{n}$. From this, a shear stress of $228 \mathrm{kPa}$ was computed for $\dot{\varepsilon}_{z x}=92 / \mathrm{a}$ in a shear band on the ice wall.

\section{RECENT THINNING OF THE ICE SHEET NEAR MIZUHO STATION, EAST ANTARCTICA \\ (Abstract)}

by

M. Nakawo, S. Fujita, S. Mae,

(Department of Applied Physics, Faculty of Engineering, Hokkaido University, Sapporo 060, Japan)

\section{S. Takahashi,}

(Kitami Institute of Technology, Kitami 090, Japan)

O. Watanabe, F. Nishio,

(National Institute of Polar Research, Kaga 1-9-10, Itabashi-ku, Tokyo 173, Japan)

\author{
and \\ F. Okuhira
}

(Gifu Prefectural Research Institute for Environmental Pollution, Yabuta, Gifu 500, Japan)

A $700 \mathrm{~m}$ long ice core from Mizuho Station has been analyzed. The orientation of the core was determined by examining the remanent magnetization of frozen "ice jam", which was formed accidentally on top of core segments during drilling. Referring to the core orientation, it was possible to re-investigate the structural characteristics of the core with respect to the stress and strain conditions at the surface.

It was found that the ice fabric throughout the core was a great-girdle pattern, which was on a vertical plane normal to the tensile axis and the flow direction at the surface. The fabric pattern was considered to have formed with increasing tensile strain in the direction of flow. Computer simulation was carried out on the formation of the great-girdle pattern. Comparing the core data with the simulation, the accumulated strain in the core ice was found to increase almost linearly with depth. From this information and the vertical strain-rate of the ice sheet measured in situ, recent thinning of the ice sheet is discussed. 